\title{
Catching Up in Broadband Regressions: Does Local Loop Unbundling Really Lead to Material Increases in OECD Broadband Uptake?"
}

July 2008

\section{Glenn Boyle}

NZ Institute for the Study of Competition and Regulation

\section{Bronwyn Howell}

NZ Institute for the Study of Competition and Regulation and Victoria University of Wellington

Wei Zhang

NZ Institute for the Study of Competition and Regulation and Motu Economic and Public Policy Research

\footnotetext{
* For helpful comments, we are grateful to Lewis Evans and Antony Srzich. We are also indebted to John de Ridder, who made his data available for our analysis and provided comments on an earlier draft. Any remaining errors or omissions are our responsibility. Corresponding author: bronwyn.howell@vuw.ac.nz
} 


\title{
Catching Up in Broadband Regressions: Does Local Loop Unbundling Really Lead to Material Increases in OECD Broadband Uptake?
}

\begin{abstract}
Local loop unbundling has been widely promulgated by policy-makers as a significant factor stimulating broadband uptake and therefore an essential component of a developing 'information economy'. Whilst empirical evidence on this issue is sparse, one recent study commissioned and published by the OECD (OECD, 2007) does find a statistically significant effect of unbundling on broadband uptake. On closer examination however, the economic magnitude of this effect is trivial. Moreover, once the error structure of the data is properly accounted for, the statistical significance disappears. As a result, the OECD report cannot be used to justify the view that local loop unbundling leads to greater broadband uptake.
\end{abstract}




\section{Catching Up in Broadband Regressions: Does Local Loop Unbundling Really Lead to Material Increases in OECD Broadband Uptake?}

\section{Introduction}

Broadband internet access, as the frontier technology via which individuals can access the internet, is widely perceived as a vital factor driving a country's economic growth potential (e.g., Crandall, Hahn \& Tardiff, 2002). Broadband penetration, typically measured as the number of connections per capita, and as reported regularly by policy institutions such as the Organisation for Economic Cooperation and Development (OECD) and the International Telecommunication Union, is widely used by policymakers to benchmark the relative potential of different countries to garner the economic benefits of internet connectivity. Rightly or wrongly, higher national levels of broadband penetration per capita have come to be equated with, if not superior performance in the emerging 'internet economy', then at least a greater potential to benefit from the economic gains that are perceived to be available. The pursuit of higher penetration levels, especially amongst the OECD countries, has become a form of international 'competition', with the policy environments of the successive 'winners' being scoured for evidence of those factors deemed to be instrumental in creating that country's 'success' (Ford, Koutsky \& Spiwak, 2007).

Policy-makers, anxious to isolate a simple policy lever that can be pulled to accelerate broadband uptake, have encouraged the creation of a substantial body of research endeavouring to identify the factors which are instrumental in determining levels of broadband uptake, and explain observed cross-country differences in broadband penetration (OECD, 2000; 2001; 2003; 2005; 2007a). A primary area of interest is whether open access policies such as local loop unbundling have a material effect upon the level of broadband uptake in a given country.

Under unbundling arrangements, competitors to an incumbent telecommunications provider can install their own equipment in incumbents' exchange facilities and lease access to 'last mile' copper connections to endconsumers. Entrants can then compete with the incumbent by providing differentiated services whilst simultaneously utilising the incumbent's investment in 'bottleneck assets'. Theoretically, unbundling of the local loop should stimulate increased 
broadband uptake by increasing product variety and putting price pressure on the incumbent (Cave, 2006). For this reason, along with its ability to induce competition where otherwise it might not have existed for increasingly privatized incumbent telecommunications firms, unbundling has been ardently advocated by policy bodies such as the Organisation for Economic Cooperation and Development (OECD) and the European Regulators Group of the European Union. However, unbundling has also been associated with some less attractive features: reducing the incentives for incumbent providers to invest in existing and new networks, and delaying the point at which entrants will invest in full stand-alone competing infrastructure, especially if the regulated access prices do not adequately compensate the incumbent for the risks associated with new technologies for which consumer demand is uncertain (Hausman \& Sidak, 2005).

Given this ambiguity, it is natural to ask whether widespread local loop unbundling has had the desired effect of materially increasing national broadband uptake levels. Such a question is not just of academic interest. Although redundant as a policy issue in the 28 OECD countries where it has been adopted, the answer can still help inform the debate and policy formulation in other countries where unbundling has not yet been implemented. It might also usefully inform the debate about whether other telecommunications networks, such as fibre-to-the-home, should also be subject to access regulation in order to further increase uptake of broadband connectivity,

Empirical evidence on this issue is limited, and yields varying conclusions. For example, some studies find that unbundling has a positive, but very small and statistically insignificant, effect on broadband uptake (e.g. Distaso, Lupi \& Manenti, 2006; Kim, Bauer \& Wildman, 2003; Cava-Ferrruela \& Alabau-Munoz, 2006); others that the effect is neither consistently positive nor statistically significant (Wallsten, 2006); and still others that it is small and transient (Denni \& Gruber, 2005). As a result of this ambiguity, the sole empirical study commissioned and published by the OECD takes on considerable importance. Using individual country data from both 2002 and 2005, OECD (2007) concludes that "unbundling....is currently more significant than platform competition in explaining broadband penetration" and recommends that "( $\mathrm{t}$ )his fact suggests that if platform competition does not materialise, government or regulatory policy aimed at increasing broadband penetration rates should focus on determining the appropriate pricing structure for the 
unbundled local loop or consider the use of subsidies to increase broadband infrastructure or penetration rates" (p20). Whilst the paper notes that the opinions expressed are those of its author (John de Ridder) and thus do not necessarily reflect the official views of the OECD itself or of the governments of its member countries, the conclusions supporting local loop unbundling are consistent with previous OECD advocacy for the policy (OECD, 2003; OECD, 2005; OECD, 2007a).

This paper subjects the OECD (2007) results to closer examination, a process that yields two principal conclusions. First, the statistically significant relationship between local loop unbundling and broadband uptake disappears once the estimation procedure is corrected to allow for standard errors that take account of clustering in the data (section 2). Second, even if such statistical issues are ignored, the estimated economic impact of unbundling on broadband uptake is essentially trivial, particularly in comparison to other factors (section 3). As a result, we conclude that the OECD (2007) analysis does not provide a robust basis for claims that local loop unbundling can be a principal means of increasing broadband penetration rates.

\section{Local loop unbundling and broadband uptake: statistical issues}

Using 2002 and 2005 data from up to 30 OECD countries, OECD (2007) estimates regression equations of the general form: ${ }^{1}$

$$
\mathrm{QTOT}=\alpha+\beta \mathrm{GUYRS}+\gamma \mathbf{X}+\varepsilon
$$

where: ${ }^{2}$

QTOT $=$ broadband connections per 100 population (measure of broadband penetration)

GUYRS $=$ number of years since the implementation of local loop unbundling (measure of unbundling presence) ${ }^{3}$

and $\mathbf{X}$ is a vector of control variables that potentially affect broadband uptake. Among the variables included in $\mathbf{X}$ are: ${ }^{4}$

\footnotetext{
12002 data appear in the appendix; 2005 data are in OECD (2007).

2 To facilitate comparison, we use the same variable notation as OECD (2007).

3 One slightly arbitrary feature of the OECD (2007) use of this variable is that, for countries that had not adopted local loop unbundling by 2005 , the 2005 value of GUYRS was set equal to zero and the 2002 value equal to -3 . In any event, truncating 2002 values of GUYRS at zero leaves all the results of this paper essentially unchanged.
} 
LNPDSL $=$ natural log of monthly price per megabit-second of DSL (in \$US PPP)

$\mathrm{AGE}=$ share of the population aged between 35 and 44 years

UURB $=$ percentage of the the population defined as urbanised

$\mathrm{CFAC}=$ non-DSL connections as a percentage of total broadband connections (measure of broadband competition)

DUMMY $=1$ if observation is for 2005,0 otherwise.

OECD (2007) employs OLS estimation of equation (1) in a variety of specifications, using both single-year (2005) and panel data. When only 2005 data are used, statistically significant estimates of $\beta$ are found only in models that exclude price (LNPDSL), suggesting that the unbundling proxy (GUYRS) is simply capturing more fundamental price effects. However, when the 2002 and 2005 data are combined in a panel, two regressions report estimates of $\beta$ that are significantly positive at the $1 \%$ level. These models appear in columns (A) and (B) of Table 1, where the terms in parentheses contain $t$-statistics based on OLS standard errors. ${ }^{5}$ As can be seen, the estimated GUYRS coefficients in these models range between 0.59 and 0.65 and have high $t$-statistics. These findings are the basis of OECD's (2007, p17) contention that unbundling is "a key explanatory variable" for broadband penetration. $^{6}$

Although these results suggest that local loop unbundling is an important stimulant of broadband uptake, the use of panel data necessitates some caution. As Petersen (2007) points out, residual clustering in panels can result in OLS standard errors containing significant bias, and hence in $t$-statistics that are considerably overstated. In the OECD (2007) data, the potential for time series clustering of residuals by country is high, given that 2005 broadband observations for each country are likely to

\footnotetext{
${ }^{4}$ The economic intuition underlying these variables is discussed in OECD (2007).

5 Although we are not able to replicate the OECD (2007, Table 6) results exactly (presumably due to data revisions), we are able to get very close. Moreover, the size and statistical significance of the GUYRS coefficient estimates are generally greater than those reported in the OECD paper.

${ }^{6}$ On the other hand, the estimated CFAC coefficient in column (B) suggests that the degree of platform competition has little impact on broadband penetration. Together, these results form the basis for the OECD (2007, p20) claim that "unbundling....is currently more significant than platform competition in explaining broadband penetration."
} 
be related to their 2002 counterparts. ${ }^{7}$ Consequently, the results in Table 1 may give a misleading impression of the importance of local loop unbundling in determining the extent of broadband penetration.

\section{Table 1: OECD (2007) Regression Analysis with Robust Standard Errors}

Data are drawn from 2002 (24 countries) and 2005 (30 countries). The dependent variable is broadband connections per 100 population (QTOT). $t$ statistics based on OLS standard errors are in parentheses; terms in square brackets are $t$-statistics based on standard errors that are robust to time series clustering. ${ }^{* *}$ and $*$ indicate significance at $1 \%$ and $5 \%$ levels respectively.

\begin{tabular}{|c|c|c|}
\hline $\begin{array}{l}\text { Variable } \\
\text { GUYRS }\end{array}$ & $\begin{array}{l}(\mathrm{A}) \\
0.587 \\
(2.69)^{* *} \\
{[1.75]}\end{array}$ & $\begin{array}{l}(\mathrm{B}) \\
0.652 \\
(2.96)^{* *} \\
{[1.86]}\end{array}$ \\
\hline LNPDSL & $\begin{array}{l}-2.014 \\
(4.05)^{* *} \\
{[4.25]^{* *}}\end{array}$ & $\begin{array}{l}-1.979 \\
(3.90)^{* *} \\
{[3.43]^{* *}}\end{array}$ \\
\hline UURB & $\begin{array}{l}0.235 \\
(4.53)^{* *} \\
{[4.02]^{* *}}\end{array}$ & $\begin{array}{l}0.259 \\
(4.92)^{* *} \\
{[4.19]^{* *}}\end{array}$ \\
\hline AGE & $\begin{array}{l}0.769 \\
(2.14)^{*} \\
{[1.63]}\end{array}$ & \\
\hline CFAC & & $\begin{array}{l}0.042 \\
(1.51) \\
{[1.53]}\end{array}$ \\
\hline DUMMY & $\begin{array}{l}6.722 \\
(5.49)^{* *} \\
{[5.52]^{* *}}\end{array}$ & $\begin{array}{l}7.067 \\
(5.40)^{* *} \\
{[5.40]^{* *}}\end{array}$ \\
\hline Constant & $\begin{array}{c}-28.90 \\
(-2.71)^{* *} \\
{[2.40]^{*}}\end{array}$ & $\begin{array}{c}-10.58 \\
(2.05)^{*} \\
{[1.69]}\end{array}$ \\
\hline Adjusted $\mathrm{R}^{2}$ & 0.75 & 0.74 \\
\hline
\end{tabular}

\footnotetext{
${ }^{7}$ Note that the use of DUMMY in the regression models accounts, at best, only for within-year clustering induced by unobserved shocks that are common to all countries, and not for the more serious issue of country-specific factors that are otherwise unaccounted for in the model.
} 
To check this possibility, we re-estimate the Table 1 models using robust standard errors - as documented in Arellano (1987) and Peterson (2007) - that are adjusted to account for within-country correlation. The resulting coefficient $t$-statistics appear in square brackets in Table $1 .^{8}$ Although this adjustment makes little difference to the precision with which most variable coefficients are estimated, one difference is striking: in both models, the GUYRS coefficient estimate is now statistically insignificant at conventional levels. That is, once possible dependence between country observations is properly accounted for, the apparent explanatory power of local loop unbundling for broadband penetration disappears.

\section{Local loop unbundling and broadband uptake: economic issues}

The analysis of section 2 casts doubt on the importance of local loop unbundling for encouraging broadband uptake, at least within the framework of OECD (2007). Readers who are otherwise sympathetic to the importance of unbundling might reasonably respond that the dataset is small and, inevitably in a field subject to rapid technological change, contains considerable noise. Consequently, the positive relationship between QTOT and GUYRS, while imprecisely estimated, may nevertheless be evidence of a real economic phenomenon.

One way to assess this argument is to calculate the economic (or quantitative) significance of the estimated unbundling effect. In column (A) of Table 1, the estimated GUYRS coefficient is 0.59 , while in column (B) it is 0.65 . That is, for each additional year that local loop unbundling has been in place, the average OECD country can expect an increase in broadband uptake of 0.59-0.65 connections per 100 of population. So, for example, a country with a population of 20 million could expect to add 118000-130000 extra broadband connections in the first year following unbundling of the local loop.

To put these numbers in context, compare them to the corresponding coefficient estimates for the year variable (DUMMY) of 6.72 and 7.07 respectively. A simple calculation then tells us that the mere elapsing of an additional year of time has an effect on broadband uptake that is 3.6 - 3.8 times larger than that of an additional year of unbundling policy being in place. This point can be further

\footnotetext{
${ }^{8}$ The coefficient estimates themselves do not, of course, change, since we continue to use OLS estimation.
} 
illustrated by applying the results of the model to individual countries. For example, it predicts that local loop unbundling in New Zealand would lead to approximately 25,000 additional broadband connections per annum. But New Zealand already had over 340,000 connections in 2005 , so the contribution of unbundling to broadband growth is small. And the model also indicates that about 90,000 more connections would be sold each year regardless of whether unbundling occurs or not.

That the simple passing of time should have such a large impact on broadband uptake is not surprising. All new technologies take time to diffuse through an economy. Different individuals value the technology differently, new applications utilising the technology are continually altering the benefits that consumers can accrue, different applications are valued differently by individuals in different contexts, and different consumers take different amounts of time to learn about the benefits that the new technology offers them, meaning they purchase at different times (Howell \& Obren, 2002; Howell, 2008). These factors lead to the emergence of a time-based S-shaped diffusion curve for broadband (Figure 1).

\section{Figure 1: Technology Diffusion Curve}

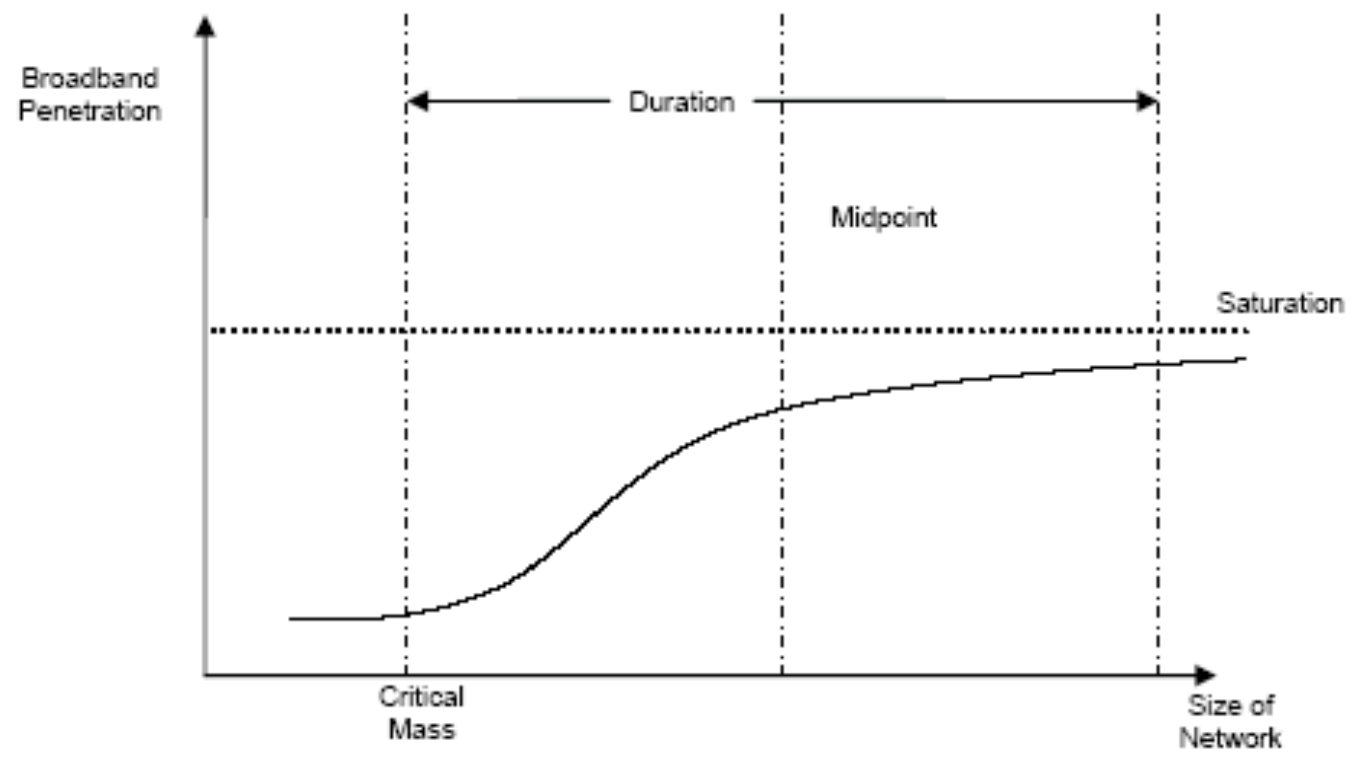

Source: Grosso (2006)

Assuming the underlying uptake pattern is identical for all countries, if the technology is first made available in different countries at different times, then at any 
given time, all countries will be at a different point of the diffusion curve. The exact position will be determined by the length of time the technology has been available. The country where it was made available first will have the highest penetration; the one where it was made available last will have the lowest. Thus, all else equal, the length of time that the technology has been available is likely to be an important determinant of broadband penetration. Indeed, the results in Table 1 indicate that it is considerably more important than the introduction of local loop unbundling.

Diffusion effects may also cause the unbundling impact observed in Table 1 limited though it is - to be overstated. To see this, note that the use of GUYRS as the indicator of local loop unbundling implicitly assumes that the impact of unbundling increases with time. While this may not be unreasonable in itself, it does mean that the estimated coefficient is unable to distinguish between true unbundling effects and simple time effects. As a result, the apparent importance of local loop unbundling for broadband uptake in the results of OECD (2007) may reflect, at least partly, simple diffusion effects. To check the potential seriousness of this problem, we extend the Table 1 regressions in two steps. First, we replace GUYRS with an indicator variable (LLU_YES) set equal to 1 if the country has implemented local loop unbundling in or prior to the year of observation and zero otherwise, i.e., a simple 'yes-no' categorization of unbundling. The results of this procedure appear in columns (A) and (B) of Table 2 and reveal that the estimated LLU_YES coefficients are insignificantly different from zero, both with and without robust standard errors. This suggests that the explanatory power of GUYRS - as reported in Table 1 - is primarily due to its time-varying component rather than to any fixed unbundling effect.

The critical question raised by this finding is whether the time-varying component of GUYRS is simply picking up broadband diffusion effects. The second component of our additional tests thus includes in regressions an additional control variable (AVAILABLE) set equal to the number of years that the broadband technology has been available for each country. ${ }^{9}$ Columns (C) and (D) of Table 2 indicate that inclusion of this variable has a considerable impact on the importance of GUYRS in explaining broadband penetration: the estimated GUYRS coefficients fall in size to less than $75 \%$ of their Table 1 counterparts and none is statistically significant, even with non-adjusted standard errors. This suggests that much of the

\footnotetext{
9 Multicollinearity problems force the deletion of DUMMY in these regressions.
} 
explanatory power attributed to GUYRS in OECD (2007) is due to its relationship with the length of time that broadband has been available. ${ }^{10}$

\section{Table 2: Further Regression Analysis}

LLU-YES equals 1 if the country has implemented local loop unbundling in or prior to the year of observation and zero otherwise; AVAILABLE equals the number of years broadband has been available in the country. All other details are the same as in Table 1.

\begin{tabular}{|c|c|c|c|c|}
\hline Variable & (A) & (B) & (C) & (D) \\
\hline GUYRS & & & $\begin{array}{l}0.435 \\
(1.59) \\
{[1.01]}\end{array}$ & $\begin{array}{l}0.459 \\
(1.67) \\
{[1.03]}\end{array}$ \\
\hline LLU_YES & $\begin{array}{l}1.708 \\
(1.02) \\
{[0.64]}\end{array}$ & $\begin{array}{l}2.247 \\
(1.31) \\
{[0.81]}\end{array}$ & & \\
\hline LNPDSL & $\begin{array}{l}-2.544 \\
(5.35)^{* *} \\
{[6.12]^{* *}}\end{array}$ & $\begin{array}{l}-2.549 \\
(5.20)^{* *} \\
{[4.74]^{* *}}\end{array}$ & $\begin{array}{l}-2.223 \\
(3.91)^{* *} \\
{[3.48]^{* *}}\end{array}$ & $\begin{array}{l}-2.168 \\
(3.78)^{* *} \\
{[3.19]^{* *}}\end{array}$ \\
\hline UURB & $\begin{array}{l}0.229 \\
(4.16)^{* *} \\
{[3.30]^{* *}}\end{array}$ & $\begin{array}{l}0.256 \\
(4.56)^{* *} \\
{[3.43]^{* *}}\end{array}$ & $\begin{array}{c}0.155 \\
(2.55)^{*} \\
{[2.53]^{*}}\end{array}$ & $\begin{array}{l}0.164 \\
(2.70)^{* *} \\
{[3.01]^{* *}}\end{array}$ \\
\hline AGE & $\begin{array}{l}0.908 \\
(2.41)^{*} \\
{[2.07]^{*}}\end{array}$ & & $\begin{array}{l}0.423 \\
(1.02) \\
{[0.97]}\end{array}$ & \\
\hline CFAC & & $\begin{array}{l}0.049 \\
(1.66) \\
{[1.75]}\end{array}$ & & $\begin{array}{l}0.004 \\
(0.14) \\
{[0.12]}\end{array}$ \\
\hline DUMMY & $\begin{array}{c}7.511 \\
(5.90)^{* *} \\
{[6.77]^{* *}}\end{array}$ & $\begin{array}{l}8.031 \\
(5.84)^{* *} \\
{[6.49]^{* *}}\end{array}$ & & \\
\hline AVAILABLE & & & $\begin{array}{l}1.429 \\
(3.40)^{* *} \\
{[3.16]^{* *}}\end{array}$ & $\begin{array}{l}1.480 \\
(3.50)^{* *} \\
{[2.95]^{* *}}\end{array}$ \\
\hline Constant & $\begin{array}{l}-30.13 \\
(-2.65)^{* *} \\
{[2.63]^{*}}\end{array}$ & $\begin{array}{l}-8.54 \\
(1.51) \\
{[1.09]}\end{array}$ & $\begin{array}{l}-14.08 \\
(1.18) \\
{[1.33]}\end{array}$ & $\begin{array}{l}-3.335 \\
(0.61) \\
{[0.52]}\end{array}$ \\
\hline Adjusted $\mathrm{R}^{2}$ & 0.75 & 0.73 & 0.67 & 0.67 \\
\hline
\end{tabular}

10 Unsurprisingly, GUYRS is strongly correlated in the data sample with AVAILABLE, which in turn is strongly correlated with QTOT: both Pearson correlation coefficients exceed 0.5 and are significantly different from zero at the $1 \%$ level. 


\section{Conclusion}

Our analysis of the data contained in OECD (2007) suggests that the contribution of local loop unbundling to the level of national broadband uptake is materially very small and, after correcting for data dependencies, statistically insignificant. Moreover, what effect there is appears to be largely spurious, reflecting the impact of increasing broadband diffusion rather than unbundling per se. Of course, additional evidence favouring the efficacy of unbundling may yet emerge as more data become available. But until such evidence appears, the case for unbundling as a stimulant of broadband penetration remains unproven. In particular, the results in OECD (2007) cannot be used to justify arguments that local loop unbundling is a necessary policy for inducing meaningful increases in national broadband uptake. 


\section{References}

Arellano, M. (1987). Computing robust standard errors for within-groups estimators. Oxford Bulletin of Economics and Statistics 49, 431-433.

Cava-Ferreruela, I., \& Alabau-Munoz, A. (2006). Broadband policy assessment: a crossnational empirical analysis. Telecommunications Policy 30, 445-463.

Cave, M. (2006). Encouraging infrastructure competition via the ladder of investment. Telecommunications Policy 30, 223-237.

Crandall, R., Hahn, R., \& Tardiff, T. (2002). The benefits of broadband and the effects of regulation. Chapter 13 (pp295-330) in Crandall, R., Alleman, J. (eds) Broadband: how should we regulate high-speed internet access? Washington, D.C.: Brookings Institution Press.

Denni, M., \& Gruber, H. (2005). The diffusion of broadband telecommunications: the role of competition. Paper presented and the International Communications Society conference, Pontevedra, Spain.

Distaso, W., Lupi, P., \& Manenti, F. (2006). Platform competition and broadband uptake: theory and empirical evidence from the European Union. Information Economics and Policy 18(1), 87-106.

Ford, G., Koutsky, T., \& Spiwak, L. (2007). The broadband performance index: a policyrelevant method of comparing broadband adoption among countries. Phoenix Center Policy Paper Number 29.

Grosso, M. (2006). Determinants of broadband penetration in OECD nations. Paper presented to the Australian Communications Policy and Research Forum. Available on http://www.networkinsight.org/verve/ resources/GrossoM.pdf .

Hausman, J., \& Sidak, G. (2005). Did mandatory unbundling achieve its purpose? Empirical evidence from five countries. Journal of Competition Law and Economics 1(1), 173245.

Howell, B. (2008). Competition, regulation and broadband diffusion: the case of New Zealand. In Dwivedi, Y., Papazafeirapoulu, A., \& Choudrie, J. (Eds) Handbook of research on global diffusion of broadband data transmission New York: Information Science Reference.

Howell, B., \& Obren, M. (2002). Broadband diffusion: lags from vintage capital, learning by doing, information barriers and network effects. ISCR Working Paper.

Kim, J., Bauer, J., \& Wildman, S. (2003). Broadband uptake in OECD countries: policy lessons from comparative statistical analysis. Paper presented at the $31^{\text {st }}$ Research Conference on Communication, Information and Internet Policy, September 19-21, Arlington, Virginia, USA.

Organization for Economic Co-Operation and Development (2007a). Communications Outlook 2007. Paris: OECD. Available on http://www.oecd.org .

Organization for Economic Co-Operation and Development (2007). Catching-up in broadband - what will it take? Working Party on Communication Infrastructures and Services Policy paper DSTI/ICCP/CISP(2007)8/FINAL, OECD, Paris. Available on http://www.oecd.org. 
Organization for Economic Co-Operation and Development (2005). Communications Outlook 2005. Paris: OECD. Available on http://www.oecd.org

Organization for Economic Co-Operation and Development (2003). Developments in Local Loop Unbundling. Paris: OECD. Available on http://www.oecd.org .

Organization for Economic Co-Operation and Development (2001). The developments of broadband access in OECD countries. Paris: OECD. Available on http://www.oecd.org.

Organization for Economic Co-Operation and Development. (2000). Local access pricing and e-commerce. Paris: OECD.

Peterson, M. (2007). Estimating standard errors in finance panel data sets: comparing approaches. Review of Financial Studies, forthcoming.

Wallsten, S. (2006). Broadband and unbundling regulations in OECD countries. Working Paper 06-16, AEI-Brookings Joint Center for Regulatory Studies.

\section{Appendix}

Table A-1: Expanded OECD Data - 2002

\begin{tabular}{|l|cccccc|}
\hline & QTOT & LNPDSL & AGE & UURB & CFAC & GUYRS \\
\hline Australia & 1.84 & 4.67 & 28.4 & 88.2 & 51.1 & 3 \\
Austria & 5.61 & 4.16 & 30.1 & 66 & 60.2 & 4 \\
Belgium & 8.67 & 2.52 & 29.3 & 97.2 & 42.1 & 2 \\
Canada & 12.11 & 3.56 & 30.5 & 80.1 & 56.4 & 6 \\
Denmark & 8.25 & 4.14 & 28.7 & 85.6 & 30.8 & 5 \\
Finland & 5.45 & 4.48 & 29.3 & 61.1 & 19.2 & 7 \\
France & 2.76 & 4.69 & 27.3 & 76.7 & 16.7 & 2 \\
Germany & 4.05 & 3.87 & 30.6 & 75.2 & 4.5 & 5 \\
Hungary & 0.65 & 4.8 & 27.7 & 66.3 & 51.2 & 1 \\
Iceland & 8.45 & 5.05 & 27.3 & 92.8 & 2.1 & 3 \\
Ireland & 0.27 & 4.87 & 26.6 & 60.5 & 68.9 & 2 \\
Italy & 1.68 & 4.2 & 28.8 & 67.6 & 14.4 & 2 \\
Japan & 6.13 & -0.02 & 26.5 & 65.8 & 27.7 & 6 \\
Luxembourg & 1.54 & 5.27 & 32.1 & 82.8 & 18.9 & 2 \\
Mexico & 0.25 & 5.49 & 29 & 76 & 68.4 & -3 \\
Netherlands & 7.04 & 3.6 & 30.1 & 80.2 & 70.1 & 5 \\
New Zealand & 1.61 & 3.38 & 28.2 & 86.2 & 15.8 & -3 \\
Norway & 4.2 & 4.26 & 28.3 & 77.4 & 31.8 & 2 \\
Poland & 0.3 & 5.08 & 28.6 & 62.1 & 87.7 & 0 \\
Spain & 2.98 & 5.31 & 28.6 & 76.7 & 80.2 & 2 \\
Sweden & 8.07 & 4.57 & 27.1 & 84.2 & 20.9 & 2 \\
Switzerland & 5.64 & 4.81 & 30.3 & 75.2 & 41.5 & -3 \\
United Kingdom & 2.32 & 4.24 & 27.7 & 89.7 & 52.0 & 2 \\
United States & 6.92 & 3.65 & 28.7 & 80.8 & 88.4 & 7 \\
\hline & & & & & & \\
Mean & 4.45 & 4.19 & 28.74 & 77.27 & 57.0 & 2.54 \\
Std. Dev & 3.28 & 1.14 & 1.38 & 10.27 & 67.4 & 2.86 \\
\hline Soure: Jol & 210.19 & & & &
\end{tabular}

Source: John de Ridder and OECD (2005:114) 